\title{
Assessment of quality of life among head and neck cancer patients
}

\author{
Forouzan Rafie, ${ }^{a}$ Molook Torabi, ${ }^{\mathrm{b}}$ Ali Taheri,, Zahra Mellat ${ }^{\mathrm{a}}$
}

\author{
${ }^{a}$ Neuroscience Research Centre, Kerman University of Medical Sciences, Kerman, Iran. \\ bDental and Oral Diseases Research Center, School of Dentistry, Kerman University of Medical Sciences, Kerman, Iran. \\ 'Department of Oral Pathology, School of Dentistry, Kerman University of Medical Sciences, Kerman, Iran. \\ Correspondence to: MolookTorabi (email: torabimolok773@gmail.com). \\ (Submitted: 09 September 2019 - Revised version received: 04 October 2019 - Accepted: 22 October 2019 - Published online: 26 February 2020)
}

\begin{abstract}
Objective This study evaluates the quality of life of the patients undergoing treatment at the oncology center in Yazd, Iran.
Methods This cross-sectional study was conducted on 29 patients with oral and head and neck cancer who were referred to the oncology center of Shahid Sadoughi hospital in Yazd between May 2015 and February 2016. Data were collected using the University of Washington Quality of Life questionnaire and a demographic questionnaire. The illness-related information was obtained from the patients' medical records. Questionnaires were administered before the treatment and 6 months after its completion. Data analysis was performed in SPSS 21 using chi-square and ANOVA tests. P-values of less than 0.05 were considered statistically significant.

Results The sample consisted of 17 (58.6\%) women and 12 (41.4\%) men with a mean age of $40.00 \pm 14.30$ years. The most frequent cancer location was the oral cavity and the most frequent treatment method was surgery. The mean score of quality of life before and after treatment was $12.60 \pm 2.81$ and $11.39 \pm 2.63$, respectively. The most important issues of the patients before and after treatment were pain and saliva, respectively. Stage 3 and 4 patients had a significantly lower quality of life than stage 1 and 2 patients.

Conclusion The study found that undergoing treatment affects some dimensions of quality of life. Hence, choosing the best treatment method with due attention to side effects and follow-up sessions is recommended.

Keywords cancer, head and neck, UW-QOL, quality of life
\end{abstract}

\section{Introduction}

Cancers of head and neck area including lips, mouth, tongue, tonsils, pharynx, larynx, hypopharynx, and salivary glands are typically challenging to handle because, unlike malignancies of other organs, they cannot be easily delimited. ${ }^{1}$ Head and neck cancers are the sixth most common cancer in the world. About $40 \%$ of these cancers occur in the mouth, ${ }^{2} 15 \%$ in the hypopharynx, and $25 \%$ in the larynx. ${ }^{3}$ Head and neck area is the position of organs that control primary functions such as respiration, swallowing, talking, and hearing and basically any organ that is associated with social interaction. ${ }^{4}$

In the case of oral cancer, research has shown an increase in the incidence of this cancer worldwide, ${ }^{5}$ and although this could be seen as a global health problem, two-thirds of the deaths due to this cancer occur in developing countries. ${ }^{6}$ Oral cancer and other head and neck malignancies have major effects such as pain, mucositis, dry mouth, and loss of taste, smell, appetite, and weight, which can severely affect the quality of life (QOL) of patients.?

Head and neck cancers are known to have significantly high morbidity rates. In addition, the side effects of surgery and radiotherapy can also undermine the QOL of patients. ${ }^{8}$ The effects on appearance and functions often change the patients' understanding and feelings and their ability to socially interact with others. Often, these patients are unable to hide the outward and functional effects of the illness, and this negatively affects their self-esteem and confidence. ${ }^{9}$ Given the major challenges that these patients must face in their lives after treatment and their need to maintain functionality despite their condition, their QOL is an important issue worthy of deep consideration. ${ }^{10}$ The QOL of patients with head and neck cancer can be improved through different therapeutic approaches. The efforts in this area have led to the development of several questionnaires and also QOL measurements becoming one of the components of treatment protocols. According to the definition of the World Health Organization, QOL is "an individual's perception of their position in life in the context of the culture and value systems in which they live and in relation to their goals, expectations, standards, and concerns." 11

In a study by Aquarwal et al. on the QOL of patients with tongue cancer, they reported significant improvements in pain, general functions, and psychological state of these patients 12 months after treatment. ${ }^{12}$ In a research carried out by Boyapati et al., an acceptable level of QOL outcome was reported for local reconstructive treatment of early tongue/floor of mouth cancer. These researchers stated that local reconstructive surgery could be highly effective in managing early tongue/floor of mouth cancers. The instrument used in this research was the University of Washington Quality of Life (UW-QOL) questionnaire. $^{11}$

In an assessment of QOL of head and neck cancer patients undergoing modern radiotherapy, Chen showed that $80 \%$ of these patients had a good overall QOL. ${ }^{13}$ In another research, head and neck cancer patients who had undergone common surgical procedures with or without complementary therapy earned higher scores in most dimensions of QOL. ${ }^{14}$ There exist strong evidence suggesting a positive relationship between the survival of people with head and neck cancer and their physical activity before treatment, and also between their survival and the change in QOL from before treatment to 6 months after. ${ }^{15}$ It has been shown that patients with advanced cancer have lower QOL and higher scores in pain, fatigue, and loss of appetite dimensions. ${ }^{2}$ A study by Villaret et al., which evaluated the QOL of treated oral cancer patients with the UW-QOL questionnaire, showed that $77 \%$ of these patients had maintained their normal or near-normal functions 12 months after treatment. This study concluded that reconstructive treatment can be very effective in maintaining the 
QOL of oral cancer patients. ${ }^{16}$ For head and neck cancer, QOL assessments can play a central role in the patient's perception and understanding of treatment and provide a preview of the outcome of interventions. ${ }^{11}$ The present study aimed to assess the QOL of head and neck cancer patients who were referred to Shahid Sadoughi hospital of Yazd ${ }^{1}$ (the only cancer treatment center of Yazd province). This assessment was performed using the UW-QOL questionnaire, which is a simple and practical instrument containing special questions for patients with head and neck cancer. ${ }^{17}$

\section{Methods}

This cross-sectional (descriptive-analytic) study was conducted on patients with head and neck cancer in Yazd province who were referred to Shahid Sadoughi hospital from May 2015 to February 2016. The data collection instrument was a QOL evaluation questionnaire and a demographic questionnaire querying age, education level, and occupation. Illness-related information, including cancer type and location, clinical stage, and treatment type were collected from the patients' medical files. QOL was evaluated using the UW-QOL questionnaire, which is a widely accepted instrument for measuring the QOL outcomes of head and neck cancers. This questionnaire consists of two parts. The first part has seven questions covering pain, appearance, swallowing, chewing, taste, and saliva. The second part has three global questions about how patients feel relative to before cancer, about their health-related QOL, and about their overall QOL. Of the seven questions contained in the first part, six are four-choice questions with scores between 0 and 3 , and one is a three-choice question with a score between 0 and 2 . The total score of the questionnaire ranges from 0 (worst) to 20 (best). Patients under the age of 18 , those with secondary cancers, and those who could not understand the questions due to mental or cognitive impairments were excluded. For illiterate patients and those who could not read or respond for any reason, the researcher read the questions and answers and recorded the responses. All patients were informed that their names and personal information will remain completely confidential and that there is no obligation in responding to questions. Subjects were selected by convenience sampling from eligible patients encountered during the study period. Data analysis was performed in SPSS 21 using chi-square and ANOVA tests. In all statistical tests, the significance level was considered to be 0.05 . All participants completed written informed consent. The study was approved by the Research Ethics Committee of Kerman Medical University code number.

\section{Results}

A total of 42 patients entered the study. Of these, 29 patients responded to all the questions both before and after the treatment. Of these 29 patients, 12 were male (41.4\%) and 17 were female $(58.6 \%)$. These patients had a mean age of $40.00 \pm 14.30$ years and an age range of between 18 and 70 years. Among these patients, the most frequent cancer location was oral cavity $(48.3 \%)$, the most frequent treatment method was surgery

${ }^{1}$ The city of Yazd is the capital of Yazd province in Iran

\begin{tabular}{|c|c|c|c|}
\hline Variable & & Number & Percent \\
\hline \multirow{2}{*}{ Gender } & man & 12 & 41.4 \\
\hline & woman & 17 & 58.6 \\
\hline \multirow{4}{*}{$\begin{array}{l}\text { Educational } \\
\text { level }\end{array}$} & Elementary & 13 & 44.8 \\
\hline & High school & 8 & 27.5 \\
\hline & Diploma & 5 & 17.2 \\
\hline & License & 3 & 10.3 \\
\hline \multirow{3}{*}{ Job } & Employee & 9 & 31.0 \\
\hline & Worker & 12 & 41.4 \\
\hline & Jobless & 8 & 27.5 \\
\hline \multirow{4}{*}{$\begin{array}{l}\text { Tumor } \\
\text { location }\end{array}$} & Oral cavity & 14 & 48.3 \\
\hline & Larynx & 7 & 24.1 \\
\hline & Oropharynx & 3 & 10.3 \\
\hline & Salivary gland & 5 & 17.2 \\
\hline \multirow{2}{*}{ Tumor stage } & Stage 1,2 & 19 & 65.5 \\
\hline & Stage 3,4 & 10 & 34.4 \\
\hline \multirow{4}{*}{$\begin{array}{l}\text { Type of } \\
\text { treatment }\end{array}$} & Surgery & 22 & 75.9 \\
\hline & Chemotherapy & 2 & 6.9 \\
\hline & Radiotherapy & 3 & 10.3 \\
\hline & Combination treatment & 2 & 6.9 \\
\hline
\end{tabular}

(75.9\%), and the most frequent education level was grade school (41.4\%). Demographic characteristics of the patients are provided in Table 1.

The mean and standard deviation of QOL scores in pain, appearance, swallowing, chewing, speech, taste, and saliva dimensions (during the past 7 days) at the onset of treatment and after its end are presented in Table 2.

The mean QOL score in this study was $12.60 \pm 2.81$ before treatment and changed to $11.39 \pm 2.63$ after treatment.

Table 3 shows the overall QOL score of the patients before and after treatment and their relations with demographic and clinical variables. As can be seen, a significant difference was

Table 2. Mean and standard deviation of QoL domains before and after treatment.

\begin{tabular}{lccccc}
\hline \multirow{2}{*}{ Quality of life } & \multicolumn{2}{c}{ Before treatment } & & \multicolumn{2}{c}{ After treatment } \\
\cline { 2 - 3 } & Mean & SD & & Mean & SD \\
\hline pain & 1.15 & 0.23 & & 2.14 & 0.27 \\
Appearance & 2.18 & 0.18 & & 1.93 & 0.31 \\
Swallowing & 1.36 & 0.56 & & 1.23 & 0.48 \\
Chewing & 1.27 & 0.32 & & 1.18 & 0.21 \\
Speech & 2.28 & 0.63 & & 2.23 & 0.38 \\
Taste & 2.25 & 0.14 & & 2.14 & 0.16 \\
Saliva & 2.11 & 0.75 & & 1.75 & 0.76 \\
\hline
\end{tabular}




\begin{tabular}{|c|c|c|c|c|c|c|}
\hline \multirow{2}{*}{ Variable } & & \multicolumn{2}{|c|}{ Before treatment } & \multicolumn{2}{|c|}{ After treatment } & \multirow{2}{*}{$P$ value } \\
\hline & & Mean & SD & Mean & SD & \\
\hline \multirow{2}{*}{ Gender } & Man & 12.23 & 3.28 & 11.25 & 2.74 & \multirow{2}{*}{$0.05<$} \\
\hline & Woman & 11.89 & 2.34 & 11.53 & 2.52 & \\
\hline \multirow{4}{*}{$\begin{array}{l}\text { Educational } \\
\text { level }\end{array}$} & Elementary & 12.21 & 3.04 & 10.27 & 2.10 & \multirow{4}{*}{$0.05<$} \\
\hline & High school & 13.85 & 4.12 & 12.52 & 3.15 & \\
\hline & Diploma & 12.94 & 2.31 & 11.79 & 2.10 & \\
\hline & License & 11.53 & 1.77 & 10.98 & 3.17 & \\
\hline \multirow{3}{*}{$\begin{array}{l}\text { Age group } \\
\text { (years) }\end{array}$} & $<40$ & 12.52 & 3.01 & 10.89 & 3.12 & \multirow{3}{*}{$0.05<$} \\
\hline & $40-59$ & 12.51 & 2.64 & 11.19 & 2.43 & \\
\hline & $\geq 60$ & 12.85 & 3.78 & 12.09 & 2.34 & \\
\hline \multirow{4}{*}{$\begin{array}{l}\text { Tumor } \\
\text { location }\end{array}$} & Oral cavity & 12.92 & 4.01 & 13.12 & 3.21 & \multirow{4}{*}{$0.05<$} \\
\hline & Larynx & 13.38 & 2.80 & 11.84 & 2.50 & \\
\hline & Oropharynx & 11.51 & 2.36 & 10.42 & 1.54 & \\
\hline & Salivary gland & 12.63 & 2.07 & 12.18 & 3.27 & \\
\hline \multirow{2}{*}{ Tumor stage } & Stage I, II & 14.07 & 3.29 & 12.09 & 2.09 & \multirow{2}{*}{$0.05>$} \\
\hline & Stage III, IV & 11.15 & 2.15 & 10.69 & 3.17 & \\
\hline \multirow{4}{*}{$\begin{array}{l}\text { Type of } \\
\text { treatment }\end{array}$} & Surgery & 13.17 & 3.37 & 12.73 & 2.28 & \multirow{4}{*}{$0.05<$} \\
\hline & Chemotherapy & 12.56 & 3.25 & 12.45 & 3.14 & \\
\hline & Radiotherapy & 12.26 & 2.15 & 10.27 & 2.15 & \\
\hline & Combination treatment & 10.41 & 2.54 & 10.11 & 2.95 & \\
\hline \multicolumn{2}{|l|}{ Total score } & 12.60 & 2.81 & 11.39 & 2.63 & $0.05>$ \\
\hline
\end{tabular}

observed between cancer stages in terms of QOL before and after treatment, in the sense that persons with stage 3 and 4 cancers had worse QOL outcomes.

The overall QOL after treatment was significantly lower than before treatment. The most frequent answers to the question "Which issues have been the most important to you during the past 7 days?" before and after treatment were pain (7 patients or $24.1 \%$ ) and saliva (8 patients or $27.6 \%$ ), respectively (Fig. 1). Answers to "health-related QOL during the past 7 days" before and after treatment are illustrated in Fig. 2. As can be seen, most people rated their QOL as "Good" before treatment and "Fair" after treatment, and the percentage of people who described their QOL as "Poor" decreased after treatment.

\section{Discussion}

Assessment of QOL of head and neck cancer patients can contribute to our understanding of the effects of these malignancies and related treatments on their daily activities and to the undergoing efforts to improve the existing support measures. ${ }^{4}$ The need for effective interventions to improve the health-related QOL of cancer patients is widely recognized. ${ }^{18}$ The mean age of the patients in this study was $40.00 \pm 14.30$, which is lower than the age range reported in other works. ${ }^{2,19}$ This difference can be attributed to the type of study and the population studied. ${ }^{2}$ In the present study, the most common cancer location was the oral cavity, which is consistent with the observations of Oliveira et al. ${ }^{2}$

In the present study, surgery was the most common method of treatment. The studies carried out by Oliveira et al. ${ }^{2}$ and Kumar et al. ${ }^{20}$ also reported the same finding. However, this is inconsistent with the reports of Østhus et al. ${ }^{21}$ and Chiou et al. ${ }^{22}$ In the present study, pain was the most prevalent problem before treatment but was considerably alleviated after treatment. Agarwal et al. also reported a decrease in pain in patients with tongue cancer after treatment. ${ }^{12}$ The study conducted by Gandhi et al. also found that pain was one of the four most important symptoms in patients with head and neck cancer. ${ }^{23}$ It has been reported that in head and neck cancer cases, pain typically affects oral function. Research has also shown that pain is a common complaint in $58 \%$ of head and neck cancer patients waiting for treatment and $30 \%$ of patients after treatment. ${ }^{24-26}$ In this study, the most frequent post-treatment complaint was saliva problem. In the study of Chen et al., the lowest score 5 years after the treatment was related to salivary dysfunction. ${ }^{13}$ Problems with swallowing, local pain, and mouth dryness are very common complaints among head and neck cancer patients. ${ }^{27}$ Salivary problems of the patients can be attributed to the methods of treatment commonly employed for head and neck cancers, including radiotherapy. In the present study, the patients who had undergone combination therapy had worse QOL outcomes. This finding is in agreement with the findings of Kessler et al. ${ }^{28}$ In this study, no statistically 
significant relationship was observed between the treatment method and the cancer-related QOL relative to before treatment. Crombie et al. also did not find a significant relationship between the treatment method and the QOL of patients. ${ }^{14}$ In the present study, overall QOL after treatment was lower than before treatment, although some improvements were also observed, most notably in pain. This study found that people with oropharynx and larynx cancer had better post-treatment QOL outcomes than those with cancer in salivary gland and oral cavity. This is consistent with the results reported by Bjordal et al..$^{29}$ In the present study, the clinical stage of cancer had a significant relationship with the QOL score, as people with stage 3 and 4 cancers had worse QOL outcomes. This is not consistent with the findings of other studies such as Gandhi et al., Lee et al., Yucel et al., ${ }^{30,31,23}$ and Torabi et al., which have found no statistically significant relationship between the clinical stage and oral health-related QOL. This inconsistency could be due to the type of the study and the questionnaire used here. ${ }^{32}$ In this study, the mean total QOL score after treatment was significantly lower than before treatment, which may be because $34.4 \%$ of the patients were in stage 3 or 4 .
Hammerlid et al. have also reported a higher frequency of dental problems, viscous saliva, loss of taste, dysphagia, and feeling of sickness among stage 3 and 4 patients. ${ }^{33}$ After treatment, in response to the question "How would you rate your health-related quality of life?" no patient rated their QOL as very poor or very well.

The most important limitation of this study was reliance on self-reports and lack of clinical examinations to assess pain, dry mouth, swallowing, and other parameters enquired in the questionnaire.

\section{Conclusion}

This study found that stage 3 and 4 head and neck cancer patients had significantly lower QOL than stage 1 and 2 patients both before and after treatment. Before treatment, patients reported that their most important problem during the preceding 7 days was pain, but after treatment, saliva was their biggest problem. Patients generally gave a better rating to their QOL after treatment.

\section{References}

1. MacCarthy D, Nunn J, Healy CM, Stassen LF, Gorman T, et al. Outcomes from the first mouth cancer awareness and clinical check-up day in the Dublin Dental University Hospital. J. Ir. Dent. Assoc. 2012;58(2):101-108.

2. Oliveira KG, von Zeidler SV, Jose RV Podestá J RV, Sena A, Evandro D Souza ED, Jeferson Lenzi J, Bissoli N S, Gouvea SA. Influence of pain severity on the quality of life in patients with head and neck cancer before antineoplastic therapy. BMC Cancer. 2014 Jan 24;14:39

3. Zevallos JP. International Head and Neck Cancer Epidemiology Consortium: Update No. 21. Head Neck. 2016:38:1447-1448.

4. Mantia IL, Rossitto F, Andaloro C. Quality of life in head and neck cancer: Patients' and family caregivers 'perceptions. Egypt. J. Ear Nose Throat Allied Scen. 2017;18(3):247-250.

5. Awojobi O, Scott E S, Newton T. Patients' perceptions of oral cancer screening in dental practice: A cross-sectional study. BMC Oral Health 2012;12:55-63.

6. Elango K J, Anandkrishnan N, Suresh A, lyer S K, Ramalyer SK, Kuriakose M A. Mouth self-examination to improve oral cancer awareness and early detection in a high-risk population. Oral Oncol. 2011:47:620-624.

7. Ehrsson YT, Langius-Eklöf A, Laurell G. Nutritional surveillance and weight loss in head and neck cancer patients. Support Care Cancer 2012:20:757765.

8. Meyer F, Fortin A, Gélinas M, Nabid A, Brochet F, Têtu B, Bairati I. Healthrelated quality of life as a survival predictor for patients with localized head and neck cancer treated with radiation therapy. J. Clin. Oncol. 2009 Jun 20;27(18):2970-6

9. Quality of life in patients treated for cancer of the oral cavity requiring reconstruction: A prospective study. Acta Otorhinolaryngol. Ital. 2008;28:120-125.

10. Zwahlen RA, Dannemann C, Grätz KW, Studer G, Zwahlen D, Moergeli H, et al. Quality of life and psychiatric morbidity in patients successfully treated for oral carity sguamous cell cancer and their wives. J. Oral Maxillofac. Surg. 2008;66(6):1125-32.

11. Boyapati RP, Shah KC, Flood V, Stassen LF. Quality of life outcome measures using UW-QOL questionnaire v4 in early oral cancer/squamous cell cancer resections of the tongue and floor of mouth with reconstruction solely using local methods. Br. J. Oral Maxillofac. Surg. 2013 Sep;51(6):502-7.

12. Agarwal SK, Munjal M, Koul R, Agarwal R. Prospective evaluation of the quality of life of oral tongue cancer patients before and after the treatment. Ann. Palliat. Med. 2014 Oct;3(4):238-43.

13. Chen AM, Daly ME, Farwell DG, Vazquez E, Courquin J Lau DH Purdy JA. Quality of life among long-term survivors of head and neck cancer treated by intensity-modulated radiotherapy. JAMA Otolaryngol. Head Neck Surg. 2014 Feb:140(2):129-33.
14. Crombie AK, Farah CS, Batstone MD. Health-related quality of life of patients treated with primary chemoradiotherapy for oral cavity squamous cell carcinoma: a comparison with surgery. Br. J. Oral Maxillofac. Surg. 2014 Feb:52(2):111-7.

15. Van Nieuwenhuizen AJ, Buffart LM, Brug J, Leemans CR, Verdonck-de Leeuw $I M$. The association between health related quality of life and survival in patients with head and neck cancer: A systematic review. Oral Oncol. 2015 Jan:51(1):1-11.

16. Villaret AB, Cappiello J, Piazza C, Pedruzzi B, Nicolai P. Quality of life in patients treated for cancer of the oral cavity requiring reconstruction: a prospective study. Acta Otorhinolaryngol. Ital. 2008;28:120-125.

17. Hassan SJ, Weymuller EA. Assessment of quality of life in head and neck cancer patients. Head Neck 1993;15:485-496.

18. Van der Meulen IC, May AM, de Leeuw JRJ, Koole R, Oosterom M, et al. Long-term effect of a nurse-led psychosocial intervention on healthrelated quality of life in patients with head and neck cancer: A randomized controlled trial. Br. J. Cancer. 2014:110:593-601.

19. Parkin DM, Bray Fl, Devesa SS: Cancer burden in the year 2000. The global picture. Eur. J Cancer 2001:37(8):4-66.

20. Kumar P, Alvi HA, Rao J, Singh BP, Jurel SK, Kumar L, Aggarwal H.Assessment of the quality of life in maxillectomy patients: A longitudinal study. J. Adv. Prosthodont. 2013 Feb;5(1):29-35.

21. Østhus AA, Aarstad AK, Olofsson J, Aarstad HJ. Prediction of survival by pretreatment health-related quality-of-life scores in a prospective cohort of patients with head and neck squamous cell carcinoma. JAMA Otolaryngol. Head Neck Surg. 2013;139(1):14-20.

22. Chiou WY, Lee MS, Ho HC, Hung SK, Lin HY, Su YC, et al. Prognostic fators and the relationship of depression and quality of life in head and neck cancer. Ind. J. Cancer. 2013;50(1):14-20.

23. Gandhi AK, Roy S, Thakar A, Sharma A, Mohanti BK. Symptom burden and quality of life in advanced head and neck cancer patients: AllMS study of 100 patients. Ind. J. Palliat. Care. 2014 Sep;20(3):189-93.

24. Connelly ST, Schmidt BL: Evaluation of pain in patients with oral squamous cell carcinoma. J. Pain 2004;5:505-510

25. Cuffari L, de Tesseroli SJT, Nemr K, Rapaport A: Pain complaint as the first symptom of oral cancer: A descriptive study. Oral. Surg. Oral Med. Oral. Pathol. Oral Radiol. Endod. 2006:102:56-61.

26. Epstein JB, Emerton S, Kolbinson DA, Le ND, Phillips N, Stevenson-Moore P Osoba D: Quality of life and oral function following radiotherapy for head and neck cancer. Head Neck 1999;21:1-11.

27. Wan Leung S, Lee TF, Chien C, Chao PJ, Tsai WL Fang FM. Health-related Quality of life in 640 head and neck cancer survivors after radiotherapy using EORTC QLQ-C30 and QLQ-H\&N35 questionnaires. BMC Cancer 2011:11:128-135. 
28. Kessler PA, Bloch-Birkholz A, Leher A, Neukam FW, Wiltfang J. Evaluation of quality of life of patients with oral squamous cell carcinoma. Comparison of two treatment protocols in a prospective study. Radiother. Oncol. 2004;70(3):275-282.

29. Bjordal K, Ahlner-Elmqvist M, Hammerlid E, Boysen M, Evensen JF, Biörklund A, Jannert M, Westin T, Kaasa S. A prospective study of quality of life in head and neck cancer patients. Part II: Longitudinal data. Laryngoscope. 2001 Aug;111(8):1440-52.

30. Lee Y-H, Lai Y-H, Yueh B, Chu P-Y, Chen Y-J, Chen S-C, et al. Validation of the University of Washington Quality of Life Chinese Version (UWQOL-C) for head and neck cancer patients in Taiwan. J. Formos. Med. Assoc. 2017:116(4):249-256

31. Yucel B, Akkaş EA, Okur Y, Eren AA, Eren MF, Karapınar H, et al. The impact of radiotherapy on quality of life for cancer patients: a longitudinal study. Support. Care Cancer. 2014;22(9):2479-2487.

32. Torabi M, Larizadeh M H, Safizadeh H, Karimi Afshar M, Modares Ahmadi N. Quality of life and OHRQoL in head and neck cancer patients in Kerman Iran. J. Oral Health Oral Epidemiol. 2012;1(2):78-82.

33. Hammerlid E, Bjordal K, Ahlner M. Prospectivestudy. Quality of life in head and neck patients.Laryngoscope 2001;111:669-680

This work is licensed under a Creative Commons Attribution-NonCommercial 3.0 Unported License which allows users to read, copy, distribute and make derivative works for non-commercial purposes from the material, as long as the author of the original work is cited properly. 